\title{
Erratum to: Toddlers' Temperament Profiles: Stability and Relations to Negative and Positive Parenting
}

\author{
Alithe L. van den Akker • Maja Deković • \\ Peter Prinzie • Jessica J. Asscher
}

Published online: 21 March 2015

(C) Springer Science+Business Media New York 2015

Erratum to: J Abnorm Child Psychol (2010) 38:485-495

DOI 10.1007/s10802-009-9379-0

The authors would like to note an error in the method section of this paper. The error is on page 487 in the description of the ages of the children in the study. At T2 and T3 the children's mean ages were 31 months $(\mathrm{SD}=6.5$, range $=19-44)$, and 36 months $(\mathrm{SD}=6.4$, range $=24-49)$ respectively, and not 36 months $(\mathrm{SD}=6.5$, range $=26-49)$ and 39 months $(\mathrm{SD}=6.5$, range $=27-51$ ), as originally described in the paper. For T4, the mean age of the children was correct (42 months), but the standard deviation was 6.3 , and the range was $30-55$ months (rather than $\mathrm{SD}=6.5$, range $=40-55$ ). This error has no implications for the analysis of the reported results, as the loadings of the $\mathrm{T} 2$ and $\mathrm{T} 3$ assessments in the growth curves were freely estimated to allow for non-linearity of change.

The online version of the original article can be found at http://dx.doi.org/ 10.1007/s10802-009-9379-0.

A. L. van den Akker $(\bowtie) \cdot$ M. Deković $\cdot$ P. Prinzie Department of Child and Adolescent Studies, Utrecht University, P.O. Box 80.140, 3508 TC Utrecht, The Netherlands e-mail: A.L.vandenAkker@uu.nl

J. J. Asscher

Research Centre for Forensic Child and Youth Care Studies,

University of Amsterdam, Nieuwe Prinsengracht 130,

Amsterdam 1018 VZ, The Netherlands 